\section{The impact of first-trimester intrauterine hematoma on adverse perinatal outcomes}

\author{
Alberto Borges Peixoto ${ }^{1,2,3}$, Taciana Mara Rodrigues da Cunha Caldas²,3, \\ Caetano Galvão Petrini' ${ }^{2}$ Ana Cecília Palma Romero², Luciano Eliziário Borges Júnior ${ }^{2}$, \\ Wellington P. Martins ${ }^{4}$, Edward Araujo Júnior ${ }^{1}$ \\ 'Department of Obstetrics, Paulista School of Medicine, Federal University of São Paulo \\ (EPM-UNIFESP), São Paulo; ${ }^{2}$ Mário Palmério University Hospital, University of Uberaba \\ (UNIUBE), Uberaba; ${ }^{3}$ Radiologic Clinic of Uberaba (CRU), Uberaba; ${ }^{4}$ Department of \\ Obstetrics and Gynecology, Ribeirão Preto Medical School, University of São Paulo (FMRP- \\ USP), Ribeiráo Preto, Brazil
}

Purpose: The aim of this study was to evaluate whether the presence of an intrauterine hematoma (IUH) on an early pregnancy ultrasound scan showing a live fetus was related to adverse perinatal outcomes.

Methods: We performed a retrospective cohort study to evaluate pregnant women who underwent an ultrasound examination in early pregnancy, between 6 weeks 0 days and 10 weeks 6 days. We compared the perinatal outcomes between women with and without firsttrimester IUH using the Mann-Whitney and Fisher exact tests. Furthermore, we performed a stepwise regression analysis to identify possible predictors of miscarriage among maternal characteristics, ultrasound parameters, and IUH.

Results: During the study period, data from 783 pregnancies were included, and the incidence of IUH was $4.5 \%$ (35 of 783). We observed a higher proportion of miscarriage following the scan $(28.6 \%$ vs. $10 \%, P=0.003)$ and a larger yolk sac diameter during the scan $(4.8 \mathrm{~mm}$ vs. $3.8 \mathrm{~mm}$, $\mathrm{P}<0.001)$ in the pregnant women with first-trimester IUH. There was no significant difference regard the prevalence of low birth weight $(L B W ; P=0.091)$, very $L B W(P=0.370)$, or extremely LBW $(P=0.600)$ between cases with IUH and without IUH, the cesarean section rate $(68 \%$ vs. $81 \%, P=0.130)$, preterm delivery ( $16 \%$ vs. $16 \%, P>0.999)$, or the incidence of first-trimester vaginal bleeding ( $31 \%$ vs. $20 \%, P=0.130)$. Moreover, heart rate $(H R)$ was the only variable that predicted miscarriage with statistical significance $(\mathrm{P}=0.017)$.

Conclusion: Women with first-trimester IUH had a higher risk of miscarriage after the ultrasound scan. HR was the only variable that predicted miscarriage with statistical significance.

Keywords: Pregnancy trimester, first; Ultrasonography; Intrauterine hematoma;

Pregnancy complications; Perinatal outcomes

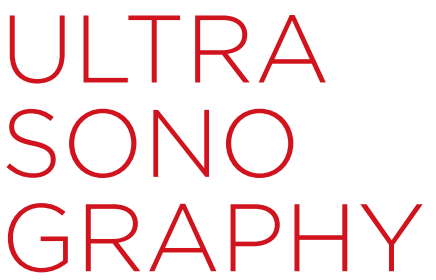

\section{ORIGINAL ARTICLE}

https://doi.org/10.14366/usg. 18006 pISSN: 2288-5919 • elSSN: 2288-5943 Ultrasonography 2018;37:330-336

Received: January 20, 2018

Revised: March 1, 2018

Accepted: March 17, 2018

Correspondence to:

Edward Araujo Júnior, PhD, Department of Obstetrics, Paulista School of Medicine, Federal University of São Paulo (EPM-UNIFESP), Rua Belchior de Azevedo, 156 apto. 111 Torre Vitoria, São Paulo, SP, CEP 05089-030, Brazil

Tel. $+55-11-37965944$

Fax. +55-11-37965944

E-mail: araujojred@terra.com.br

This is an Open Access article distributed under the terms of the Creative Commons Attribution NonCommercial License (http://creativecommons.org/ licenses/by-nc/3.0/) which permits unrestricted noncommercial use, distribution, and reproduction in any medium, provided the original work is properly cited.

Copyright @ 2018 Korean Society of Ultrasound in Medicine (KSUM)

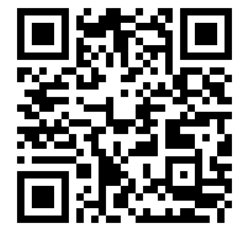

How to cite this article:

Peixoto $A B$, da Cunha Caldas TMR, Petrini CG, Romero $A C P$, Borges Júnior LE, Martins WP, et al. The impact of first-trimester intrauterine hematoma on adverse perinatal outcomes. Ultrasonography. 2018 0ct;37(4):330-336. 


\section{Introduction}

Intrauterine hematoma (IUH) is a common complication in early pregnancy, but it can randomly occur throughout pregnancy $[1,2]$. IUH is frequently observed in normal pregnancies, with a prevalence ranging from $0.5 \%$ to $39.5 \%$ depending upon the study population. In the first trimester, IUHs vary in size and location, but are smaller than those that occur in the second and third trimesters [3-5]. IUHs are usually hypoechoic, crescent-shaped areas separating the uterine wall and chorion, whereas an acute hemorrhage is hyperechogenic to isoechogenic compared with the placenta [6]. In some cases, IUH may be associated with a variable amount of bleeding, placing the lives of the mother and fetus at risk $[1,7]$.

Some studies have shown that in ongoing spontaneous pregnancies, the presence of IUHs is associated with an increased risk of abnormal pregnancy outcomes, including preeclampsia, miscarriage, fetal growth restriction, and preterm delivery [8-11]. Controversies remain regarding the prognostic value of IUH volume, gestational age (GA) at IUH diagnosis, and the simultaneous presence of vaginal bleeding [12]. Some studies have reported that women with IUH were not at a higher risk of adverse pregnancy outcomes than those without IUH $[13,14]$.

The primary aim of the present study was to evaluate whether first-trimester IUH was associated with birth weight or a higher incidence of miscarriage, stillbirth, cesarean delivery (C-section), and preterm birth compared with pregnancies without IUH The secondary objective was to evaluate whether there were any significant differences in terms of crown-rump length (CRL), mean gestational sac diameter (GSD), mean yolk sac diameter (YSD), and mean amniotic sac diameter (ASD) in pregnancies with IUH. Furthermore, we aimed to identify maternal characteristics and/or ultrasound parameters that can be used as predictors of miscarriage.

\section{Materials and Methods}

We performed a retrospective cohort study between February 2012 and November 2016 with pregnant women who underwent ultrasound scans early in pregnancy. The subjects were classified into two groups depending on whether IUH was observed. Ultrasound and outcome data were stored in a database (Astraia Software $\mathrm{GmbH}$, Munich, Germany) for subsequent analysis. This study was approved by the local ethics committee. Consent forms were not required owing to the retrospective study design.

The inclusion criteria were as follows: (1) singleton pregnancies with GA between 6 weeks 0 days and 10 weeks 6 days as determined by transvaginal ultrasound measurements of CRL; (2) the absence of fetal structural malformations or chromosomal abnormalities in the first-trimester ultrasound examination, with confirmation in the postnatal period; and (3) the presence of IUH. The exclusion criteria were as follows: nonviable embryos without a detectable heartbeat and embryos with pathological features, including fibroids, endometrial polyps, and Müllerian malformations.

Miscarriage was defined as births with a weight of $<500 \mathrm{~g}$ or at $<22$ weeks of gestation [15], and stillbirth was defined as nonviable neonates with a weight of $>500 \mathrm{~g}$ or at $>22$ weeks of gestation [15].

Ultrasound scans were performed at a tertiary university hospital. The pregnant woman was requested to empty her bladder and was then placed in a dorsal lithotomy position. The transvaginal ultrasound examination was performed using a Voluson E6 system (GE Healthcare, Zipf, Austria) with an RIC 5-9W probe. The scans were performed by three examiners with Fetal Medicine Foundation Certificate accreditation and significant experience in obstetric ultrasound imaging. All CRL measurements were made transvaginally $[16,17]$; the gestational sacs were measured in three orthogonal views, and the mean diameter was determined. Whenever possible, additional structures, including YSD and ASD, were also measured, and the mean values were determined [18].

An IUH was defined as a collection of fluid below the placenta or fetal membranes that manifested as a crescent-shaped image (Fig. 1). The mean diameter of an IUH was defined as the mean of the three orthogonal measurements obtained from the hypoechoic, crescent-shaped areas. We did not classify the IUHs according to the percentage of gestational sac.

Birth weight was categorized according to the World Health Organization classification as adequate weight $(2,500-4,200 \mathrm{~g})$ and low birth weight ( $L B W ; \leq 2,449 \mathrm{~g}$ ) at term delivery regardless of GA [19]. LBW was also subcategorized as very LBW (VLBW; $<1,500 \mathrm{~g})$ and extremely LBW (ELBW; <1,000 g) [19].

Data were transferred to an Excel spreadsheet (Microsoft Corp., Redmond, WA, USA) and analyzed using PASW version 18.0 (SPSS Inc., Chicago, IL, USA). The pregnant women were classified into two groups depending on the presence of IUH. The following maternal characteristics and ultrasound parameters were expressed as median, interquartile range, and ranges: age, height, weight, body mass index (BMI), number of pregnancies, parity, GA at delivery, birth weight, hematoma size, CRL, GA at the time of ultrasound examination, GSD, amniotic sac diameter, and YSD. Spontaneous conception, smoking, alcohol, first-trimester bleeding, diabetes, hypertension, the live birth rate, the C-section rate, and preterm delivery were the maternal characteristics that were expressed as percentages. The non-parametric quantitative variables were compared using the Mann-Whitney test. Qualitative variables were compared using the Fisher exact test. We performed a stepwise 


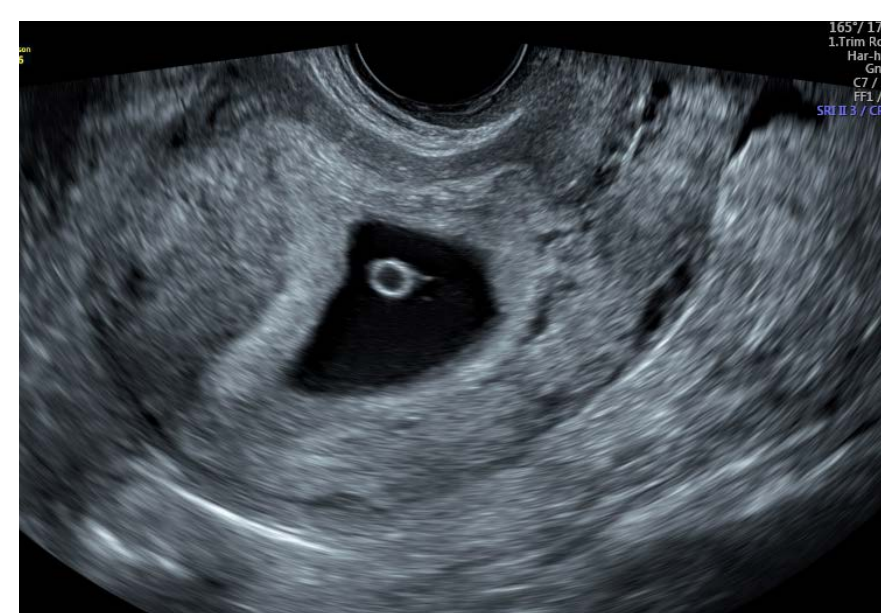

A

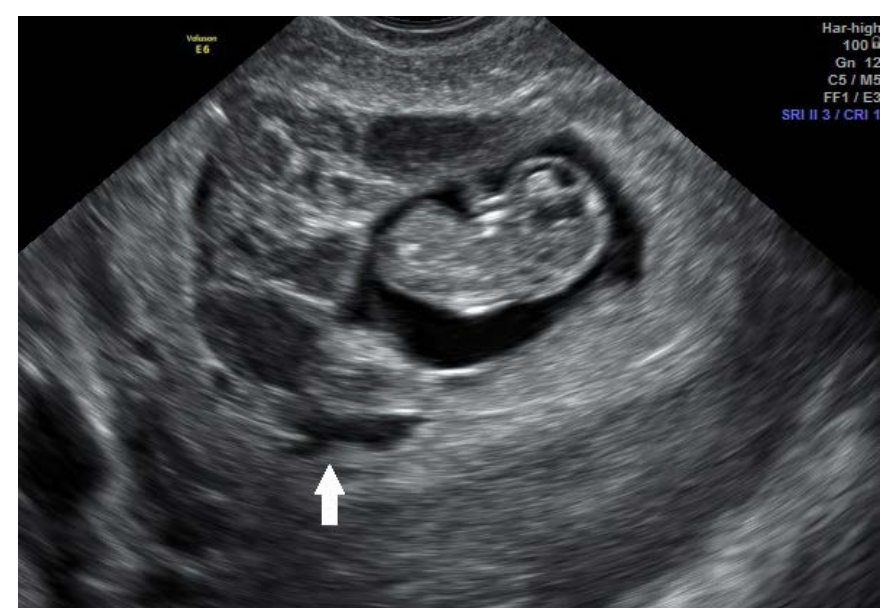

C

regression analysis to identify possible predictors of miscarriage among maternal characteristics, ultrasound parameters, and IUH. In all analyses, the level of significance was considered to be $\mathrm{P}<0.05$.

\section{Results}

During the study period, 1,985 pregnant women underwent an ultrasound examination early in pregnancy. Of them, 1,202 were excluded from the study for the following reasons: a GA of less than 6 weeks $(n=49)$, a non-viable intrauterine pregnancy in the initial scan $(n=233)$, and loss to follow-up $(n=920)$. Therefore, we only included the data from the 783 remaining pregnancies in the final analysis (Fig. 2).

There were no significant differences between the two groups in terms of CRL, GSD, ASD, birth weight, or GA at delivery. Table 1 shows the ultrasound parameters and maternal characteristics. Pregnancies with IUH showed a significantly greater YSD than

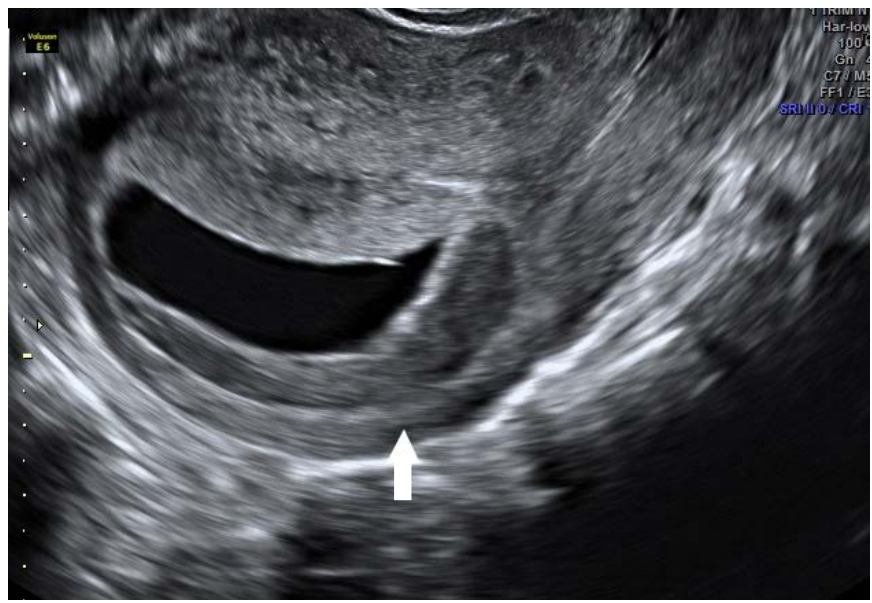

B

Fig. 1. Intrauterine hematoma in the first trimester.

A. Longitudinal view of a normal transvaginal ultrasound scan from early pregnancy without intrauterine hematoma (IUH) is seen. $B$. Sonogram of a resolving IUH shows a hypoechoic crescent-shaped area separating the uterine wall and chorion (arrow). C. Sonogram of an acute IUH shows a hyperechogenic crescent-shaped area separating the uterine wall and chorion (arrow).

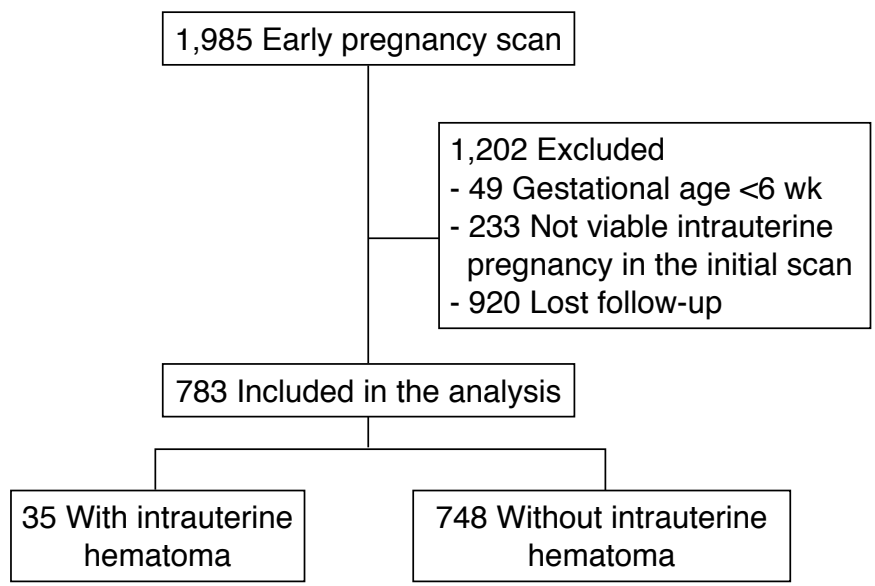

Fig. 2. Flow diagram showing the patient assessment process.

pregnancies without IUH ( $4.8 \mathrm{~mm}$ vs. $3.8 \mathrm{~mm}, \mathrm{P}<0.001$ ). There was no significant difference in the incidence of $L B W(P=0.091), V L B W$ 
$(P=0.370)$, or $E L B W(P=0.604)$ between the two groups.

In the first trimester, the incidence of IUH was $4.5 \%$ (35 of 747). A history of vaginal bleeding was more common (31\% vs. $20 \%$, $\mathrm{P}=0.130$ ) among the women with IUH (11 of 35) than among the women without IUH (151 of 747). We observed a significantly higher proportion of miscarriages among the women with IUH than among the women without IUH ( $28.6 \%$ vs. $10.0 \%, P=0.003)$ (Table 2). There was no significant difference in terms of the IUH size between cases of miscarriage and live birth $(P=0.593)$. Although there were no stillbirths among the women with IUH, two stillbirths were observed among the women without IUH ( $P>0.999)$. There were no significant differences in the preterm birth or $\mathrm{C}$-section rates between the groups.

The stepwise regression analysis (including maternal age, BMI, and IUH size) first showed that only YSD was an independent parameter that predicted miscarriage $(P=0.032)$. However, after the inclusion of heart rate (HR) in the analysis, YSD lost its statistical significance and HR became the only variable that predicted miscarriage with statistical significance $(P=0.017)$.

\section{Discussion}

In our study, we evaluated whether first-term IUH was associated with higher rates of miscarriage, stillbirth, C-section, preterm birth, and LBW. Moreover, we evaluated the principal early-pregnancy ultrasound parameters to identify variables that could be used as predictors of miscarriage in pregnancies with IUH.

We found that the number of pregnancies and parity were significantly higher among the women with IUH. In a retrospective study conducted by Biesiada et al. [20] that compared 41 women with first-trimester IUH and controls, they observed that IUH was more frequent among multiparous pregnant women than among women with low parity. The miscarriage rate increases with maternal age [21], parity [21], and the presence of IUH [7]. In our study, no other maternal characteristics or ultrasound parameters were found between the IUH and non-IUH groups.

IUH is a common finding in scans during the first trimester of pregnancy. Our analysis yielded an overall incidence of IUH that was higher than that reported by Nagy et al. [11] (4.5\% vs. 3.1\%) and Ball et al. [9] (4.5\% vs. 1.3\%), but lower than that reported by Xiang et al. [12] (4.5\% vs. 13.5\%). The clinical implications of an IUH during the first trimester of pregnancy are unclear. Some authors have reported an association with miscarriage [22] and other adverse pregnancy outcomes, including preterm delivery [11], LBW [8-11], and stillbirth [9]. The mechanism of the association between IUH and adverse perinatal outcomes is unclear [23].

Table 1. Ultrasound and maternal characteristics of pregnant women with and without first-trimester IUH

\begin{tabular}{|c|c|c|c|c|c|c|c|c|c|}
\hline & \multicolumn{4}{|c|}{ With IUH $(n=35)$} & \multicolumn{4}{|c|}{ Without IUH $(n=747)$} & \multirow{2}{*}{ - P-value } \\
\hline & No. & Median & IQR & Range & No. & Median & IQR & Range & \\
\hline Hematoma size (mm) & 35 & 17.0 & $12.0-21.0$ & $2.0-49.0$ & - & - & - & - & - \\
\hline Age (yr) & 35 & 28.0 & $23.0-33.0$ & $16.0-43.0$ & 732 & 28.0 & $23.0-32$ & $13.0-44.0$ & 0.930 \\
\hline GA at scan (wk) & 35 & 8.1 & $7.0-8.9$ & $6.0-10.9$ & 747 & 8.3 & $7.3-9.4$ & $6.0-10.9$ & 0.480 \\
\hline $\mathrm{CRL}(\mathrm{mm})$ & 32 & 16.0 & $8.0-28.7$ & $3.7-54.0$ & 464 & 17.0 & $10.6-25.3$ & $2.1-52.0$ & 0.540 \\
\hline HR (bpm) & 32 & 160.0 & $133.0-169.0$ & $113.0-190.0$ & 348 & 163.0 & $143.0-170.0$ & $74.0-191.0$ & 0.310 \\
\hline Weight (kg) & 19 & 64.0 & $59.0-73.0$ & $49.0-100.0$ & 664 & 70.0 & $62.0-80.0$ & $42.0-136.0$ & 0.160 \\
\hline Height (cm) & 18 & 162.0 & $159.0-165.0$ & $155.0-176.0$ & 594 & 163.0 & $158.0-167.0$ & $145.0-180.0$ & 0.660 \\
\hline $\mathrm{BMI}\left(\mathrm{kg} / \mathrm{m}^{2}\right)$ & 18 & 25.3 & $22.7-29.5$ & $18.1-34.5$ & 588 & 26.3 & $23.5-29.9$ & $16.9-48.6$ & 0.340 \\
\hline No. of gestations & 19 & 2.0 & $2.0-4.0$ & $1.0-6.0$ & 689 & 2.0 & $1.0-2.0$ & $1.0-7.0$ & 0.010 \\
\hline Parity number & 19 & 1.0 & $1.0-2.0$ & $0-3.0$ & 681 & 0 & $0-1.0$ & $0-5.0$ & 0.004 \\
\hline No. of abortions & 19 & 0 & $0.0-1.0$ & $0-3.0$ & 689 & 0 & $0-0$ & $0-5.0$ & 0.280 \\
\hline $\begin{array}{l}\text { Gestational sac diameter } \\
(\mathrm{mm})\end{array}$ & 34 & 32.0 & $24.0-39.6$ & $2.7-71.0$ & 286 & 31.7 & $22.9-40.3$ & $4.0-61.2$ & 0.900 \\
\hline $\begin{array}{l}\text { Amniotic sac diameter } \\
(\mathrm{mm})\end{array}$ & 9 & 21.0 & $17.0-27.0$ & $9.0-34.0$ & 120 & 23.0 & $14.0-31.0$ & $1.0-43.0$ & 0.670 \\
\hline Yolk sac diameter (mm) & 25 & 4.8 & $3.7-6.0$ & $2.0-6.8$ & 659 & 3.8 & $3.2-4.3$ & $1.5-8.0$ & $<0.001$ \\
\hline Birth weight (g) & 25 & $3,000.0$ & $2,643.0-3,300.0$ & $1,840.0-3,500.0$ & 252 & $3,145.0$ & $2,770.0-3,450.0$ & $605.0-4,970.0$ & 0.183 \\
\hline GA at delivery (wk) & 25 & 38.9 & $37.7-39.4$ & $32.9-42.3$ & 661 & 38.6 & $37.7-39.4$ & $25.1-43.0$ & 0.931 \\
\hline
\end{tabular}

IUH, intrauterine hematoma; IQR, interquartile range; GA, gestational age; CRL, crown-rump length; HR, heart rate; BMI, body mass index.

a)P-value assessed using the Mann-Whitney test. 
Table 2. Maternal demographic data of pregnant women with and without first-trimester intrauterine hematoma

\begin{tabular}{lccc}
\hline & $\begin{array}{c}\text { With IUH } \\
(\mathrm{n}=35)\end{array}$ & $\begin{array}{c}\text { Without IUH } \\
(\mathrm{n}=747)\end{array}$ & P-value $^{\mathrm{a})}$ \\
\hline Spontaneous conception & $35 / 35(100)$ & $740 / 747(99.0)$ & $>0.999$ \\
Smoking & $0 / 19(0)$ & $34 / 677(5.0)$ & 0.620 \\
Alcohol & $2 / 19(11.0)$ & $22 / 676(3.0)$ & 0.140 \\
First-trimester bleeding & $11 / 35(31.0)$ & $151 / 747(20.0)$ & 0.130 \\
Diabetes & $0 / 35(0)$ & $8 / 747(1.0)$ & $>0.999$ \\
Hypertension & $0 / 35(0)$ & $29 / 747(4.0)$ & 0.390 \\
Miscarriage & $10 / 35(28.6)$ & $75 / 747(10.0)$ & 0.003 \\
C-section & $17 / 25(68.0)$ & $538 / 666(81.0)$ & 0.130 \\
Preterm delivery & $4 / 25(16.0)$ & $105 / 661(16.0)$ & $>0.999$ \\
Stillbirth & $0 / 25(0)$ & $2 / 666(0.3)$ & $>0.999$
\end{tabular}

Values are presented as number (\%).

IUH, intrauterine hematoma; C-section, cesarean section.

a) P-value assessed by the Fisher exact test.

Premature perfusion of the Intervillous space, shallow trophoblast invasion, impaired angiogenesis, and weakness of the retroplacental area may be possible mechanisms of adverse perinatal outcomes $[10,23]$.

In a systematic review and meta-analysis performed by Tuuli et al. [23] of 1,735 women with subchorionic hematoma and 70,703 controls, IUH was found to be associated with an increased risk of miscarriage, stillbirth, abruptio placentae, preterm birth, and premature rupture of membranes. According to previous studies, the risk of perinatal death and stillbirth was higher among women with a large IUH, although a large IUH was associated with vaginal bleeding $[9,11]$, whereas the increased risk of preterm birth among women with IUH appeared to be independent of vaginal bleeding $[2,4,9]$. In our study, we likewise found a higher rate of miscarriage in the IUH group; however, we did not observe any difference in birth weight between the groups. Furthermore, we did not observe any statistically significant differences in stillbirth, GA at delivery, preterm birth, or the C-section rate.

$\mathrm{IUH}$, a subchorionic hemorrhage, is composed of a collection of blood or serum between the chorion and decidua. This finding may also be linked to vaginal bleeding. This type of subchorionic hemorrhage may arise from the inability of blood to drain out through the cervix. Alternatively, subchorionic hemorrhage may reflect a greater degree of bleeding, which cannot be drained or resorbed in a given period [9]. While Nagy et al. [11] reported that $70 \%$ of patients with IUH reported vaginal bleeding, in our study only a small proportion of women with IUH $(31 \%)$ reported vaginal bleeding during the first trimester of pregnancy.

The yolk sac (YS) is responsible for exchange between the human embryo and mother before the placental circulation is established. It facilitates nutritional, metabolic, endocrine, immunological, and hematopoietic functions during organogenesis [24]. Its usual sonographic appearance has been defined as a 3- to 5-mm-wide anechoic round structure that is encircled by a regular echogenic rim [25]. Grisolia et al. [26] reported that YSD slightly increased with $G A$, although this association was not statistically significant. The overall mean YSD ranges from $3.2 \pm 0.7$ to $4.8 \pm 0.7 \mathrm{~mm}[25,26]$. In our study, the median YSD was $3.8 \mathrm{~mm}$ among the women without IUH. Some studies have reported that abnormal sonographic findings related to the size, shape, and internal structure of the YS could be used to predict gestational outcomes [25,27-29]. Indeed, pregnancies with a YSD $\geq 5 \mathrm{~mm}$ have been associated with a significantly higher risk of miscarriage (odds ratio, 14.25; $95 \%$ confidence interval, 3 to $66.7 ; P=0.005)$ [27]. To the best of our knowledge, no study has compared YSD according to the presence of IUH. In our study, we found that the median YSD among women with IUH was statistically significantly higher than in those without IUH ( $4.8 \mathrm{~mm}$ vs. $3.8 \mathrm{~mm}$, respectively; $\mathrm{P}<0.001$ ).

Previous studies have shown GSD and CRL to increase with GA [26]. A smaller GSD for a given CRL implies a reduced volume of amniotic and/or coelomic fluid and is likely to reflect impaired placentation [30]. However, in our study, no significant differences in GSD or CRL were observed between the two groups.

Our study used a stepwise regression analysis to identify maternal characteristics and ultrasound parameters that could be predictors of miscarriage in pregnancies with first-trimester IUH. YSD was the only independent parameter associated with the prediction of miscarriage. However, after the inclusion of HR, YSD lost statistical significance and HR became the only variable that predicted miscarriage with statistical significance. Pillai et al. [31] reported that fetal bradycardia showed a sensitivity of $68.41 \%$ and a specificity of $97.84 \%$ for predicting miscarriage. To the best of our knowledge, no previous study has assessed the role of HR in predicting miscarriage in pregnancies with IUH.

Our study had certain limitations. First, this was a retrospective study and involved a relatively small study population, with GA between 6 weeks 0 days and 10 weeks 6 days. Moreover, as only three experienced examiners performed the ultrasound scans, the variability in the ultrasound and Doppler parameter measurements may have been significantly lower than is commonly encountered in clinical practice.

In conclusion, our study demonstrated that IUH was associated with a higher proportion of miscarriage and a larger YSD among women with IUH in comparison to women without IUH. However, there were no significant differences between these two groups of patients in terms of birth weight, the C-section rate, or preterm birth. 
HR was the only variable that predicted miscarriage with statistical significance in pregnancies with IUH.

ORCID: Alberto Borges Peixoto: http://orcid.org/0000-0002-1655-3609; Edward Araujo Júnior: http://orcid.org/0000-0002-6145-2532

\section{Conflict of Interest}

No potential conflict of interest relevant to this article was reported.

\section{References}

1. Leite J, Ross P, Rossi AC, Jeanty P. Prognosis of very large firsttrimester hematomas. J Ultrasound Med 2006;25:1441-1445.

2. Ott J, Pecnik P, Promberger R, Pils S, Binder J, Chalubinski KM. Intra- versus retroplacental hematomas: a retrospective casecontrol study on pregnancy outcomes. BMC Pregnancy Childbirth 2017;17:366.

3. Seki H, Kuromaki K, Takeda S, Kinoshita K. Persistent subchorionic hematoma with clinical symptoms until delivery. Int I Gynaecol Obstet 1998;63:123-128.

4. Johns J, Hyett J, Jauniaux E. Obstetric outcome after threatened miscarriage with and without a hematoma on ultrasound. Obstet Gynecol 2003;102:483-487.

5. Ji W, Li W, Mei S, He P. Intrauterine hematomas in the second and third trimesters associated with adverse pregnancy outcomes: a retrospective study. J Matern Fetal Neonatal Med 2017;30:21512155.

6. Mantoni M, Pedersen JF. Intrauterine haematoma: an ultrasonic study of threatened abortion. Br J Obstet Gynaecol 1981;88:47-51.

7. van Oppenraaij RH, Jauniaux E, Christiansen OB, Horcajadas $J A$, Farquharson RG, Exalto $N$, et al. Predicting adverse obstetric outcome after early pregnancy events and complications: a review. Hum Reprod Update 2009;15:409-421.

8. Maso G, D'Ottavio G, De Seta F, Sartore A, Piccoli M, Mandruzzato G. First-trimester intrauterine hematoma and outcome of pregnancy. Obstet Gynecol 2005;105:339-344.

9. Ball RH, Ade CM, Schoenborn JA, Crane JP. The clinical significance of ultransonographically detected subchorionic hemorrhages. Am J Obstet Gynecol 1996;174:996-1002.

10. Jauniaux E, Van Oppenraaij RH, Burton GJ. Obstetric outcome after early placental complications. Curr Opin Obstet Gynecol 2010;22:452-457.

11. Nagy S, Bush M, Stone J, Lapinski RH, Gardo S. Clinical significance of subchorionic and retroplacental hematomas detected in the first trimester of pregnancy. Obstet Gynecol 2003;102:94-100.

12. Xiang L, Wei Z, Cao Y. Symptoms of an intrauterine hematoma associated with pregnancy complications: a systematic review. PLoS One 2014;9:e111676.
13. Falco P, Milano V, Pilu G, David C, Grisolia G, Rizzo N, et al. Sonography of pregnancies with first-trimester bleeding and a viable embryo: a study of prognostic indicators by logistic regression analysis. Ultrasound Obstet Gynecol 1996;7:165-169.

14. Tower $\mathrm{CL}$, Regan L. Intrauterine haematomas in a recurrent miscarriage population. Hum Reprod 2001;16:2005-2007.

15. Ministério da Saúde. Manual Técnico de Pré-natal e Puerpério: Atenção qualificada e Humanizada [Internet]. Brasília: Ministério da Saúde, 2006 [cited 2018 Feb 9]. Available from: http://bvsms. saude.gov.br/bvs/publicacoes/manual_pre_natal_puerperio_3ed. pdf.

16. Salomon LJ, Bernard M, Amarsy R, Bernard JP, Ville Y. The impact of crown-rump length measurement error on combined Down syndrome screening: a simulation study. Ultrasound Obstet Gynecol 2009;33:506-511.

17. Salomon LJ, Alfirevic Z, Bilardo CM, Chalouhi GE, Ghi T, Kagan KO, et al. ISUOG practice guidelines: performance of first-trimester fetal ultrasound scan. Ultrasound Obstet Gynecol 2013;41:102-113.

18. Oh JS, Wright $G$, Coulam CB. Gestational sac diameter in very early pregnancy as a predictor of fetal outcome. Ultrasound Obstet Gynecol 2002;20:267-269.

19. World Health Organization. International statistical classification of diseases and related health problems. 10th rev. 2nd ed. Geneva: World Health Organization, 2004.

20. Biesiada L, Krekora M, Krasomski G. Subchorionic hematoma as a risk factor of pregnancy and delivery in women with threatening abortion. Ginekol Pol 2010;81:902-906.

21. Cohain JS, Buxbaum RE, Mankuta D. Spontaneous first trimester miscarriage rates per woman among parous women with 1 or more pregnancies of 24 weeks or more. BMC Pregnancy Childbirth 2017;17:437.

22. Jauniaux E, Johns J, Burton GJ. The role of ultrasound imaging in diagnosing and investigating early pregnancy failure. Ultrasound Obstet Gynecol 2005;25:613-624.

23. Tuuli MG, Norman SM, Odibo AO, Macones GA, Cahill AG. Perinatal outcomes in women with subchorionic hematoma: a systematic review and meta-analysis. Obstet Gynecol 2011;117:1205-1212.

24. Pereda J, Niimi G. Embryonic erythropoiesis in human yolk sac: two different compartments for two different processes. Microsc Res Tech 2008;71:856-862.

25. Lindsay DJ, Lovett IS, Lyons EA, Levi CS, Zheng XH, Holt SC, et al. Yolk sac diameter and shape at endovaginal US: predictors of pregnancy outcome in the first trimester. Radiology 1992;183:115118.

26. Grisolia G, Milano K, Pilu G, Banzi C, David C, Gabrielli S, et al. Biometry of early pregnancy with transvaginal sonography. Ultrasound Obstet Gynecol 1993;3:403-411.

27. Tan S, Gulden Tangal N, Kanat-Pektas M, Sirin Ozcan A, Levent Keskin $\mathrm{H}$, Akgunduz $\mathrm{G}$, et al. Abnormal sonographic appearances 
of the yolk sac: which can be associated with adverse perinatal outcome? Med Ultrason 2014;16:15-20.

28. Berdahl DM, Blaine J, Van Voorhis B, Dokras A. Detection of enlarged yolk sac on early ultrasound is associated with adverse pregnancy outcomes. Fertil Steril 2010;94:1535-1537.

29. Bae $S$, Karnitis J. Triple ultrasound markers including fetal cardiac activity are related to miscarriage risk. Fertil Steril 2011;96:11451148.
30. Papaioannou GI, Syngelaki A, Maiz N, Ross JA, Nicolaides KH. Ultrasonographic prediction of early miscarriage. Hum Reprod 2011;26:1685-1692.

31. Pillai RN, Konje JC, Richardson M, Tincello DG, Potdar N. Prediction of miscarriage in women with viable intrauterine pregnancy: a systematic review and diagnostic accuracy meta-analysis. Eur J Obstet Gynecol Reprod Biol 2018;220:122-131. 